\title{
SIG@LV: Sistema de Gerenciamento Acadêmico Learning Vectors
}

\author{
Gilvandenys Leite Sales ${ }^{1}$, Ricky Persivo Paz ${ }^{1}$, Allyson Bonetti França ${ }^{1}$ \\ ${ }^{1}$ Programa de Pós-graduação em Ciência da Computação - Instituto Federal do Ceará \\ (IFCE) \\ CEP 61 939-140 - Fortaleza - CE - Brasil \\ \{denyssales@ifce.edu.br, rickypaz@gmail.com, allysonbonetti@gmail.com\}
}

\begin{abstract}
Resumo. Este artigo trata da concepção, modelagem e desenvolvimento do software SIG@LV. Aplicado ao Moodle 2.X, este modelo de avaliação formativa faz uso de um instrumento baseado em projeções de vetores (Vetores-Aprendizagem), vale-se de linguagem iconográfica (LV Ícones) associados a menções qualitativas (Muito Bom; Bom; Regular; Fraco; Não satisfatório) em substituição ao tradicional sistema de notas. Seu propósito é ser intuitivo e facilitador de intervenções pedagógicas. Incorporado às ferramentas fórum de discussão, chat, wiki, tarefa e quiz; e, validado em turmas semipresenciais e presenciais de graduação do IFCE, mostrou-se motivador e regulador de aprendizagens.
\end{abstract}

\section{Cenário de Uso}

Denominado SIG@LV - Sistema de Gerenciamento Acadêmico Learning Vectors - ele se constitui num sistema de gerenciamento de notas qualitativo, por fazer uso de linguagem iconográfica na mediação avaliativa e, quantitativo, por modelar através de vetores, a nota final do aluno em cada atividade síncrona ou assíncrona no Ambiente Virtual de Aprendizagem (AVA).

O SIG@LV, implementado como um Plugin no Moodle, foi aplicado em turmas semipresenciais e em turmas presenciais de graduação do IFCE.

A base de seu desenvolvimento é o Modelo Learning Vectors - Modelo LV (SALES, 2010 e 2012) aplicado ao Moodle 1.9 e versões subsequentes, atualmente atualizado para a versão Moodle 2.5.

Por incorporar o caráter afetivo e formativo, por meio a mediação iconográfica dos LV Ícones, esta atualização trouxe mais dinamismo na avaliação formativa de fóruns e chats, pois não é necessário mais clicar em "salvar"; agrupou as informações, antes separadas, no acompanhamento da frequência do cursista nas atividades; possibilitou a visualização por parte do cursista das configurações das avaliações no curso e também incluiu no mapa de notas uma coluna para nota de questionários (quizzes).

O Modelo LV de avaliação envolve cursistas e professor/Tutor em constante interação, dialogia, aprendizagem colaborativa e troca de feedbacks (Figura 1). 


\section{Figura 1 - Modelo Tecno-Metodológico de Avaliação Formativa LV}

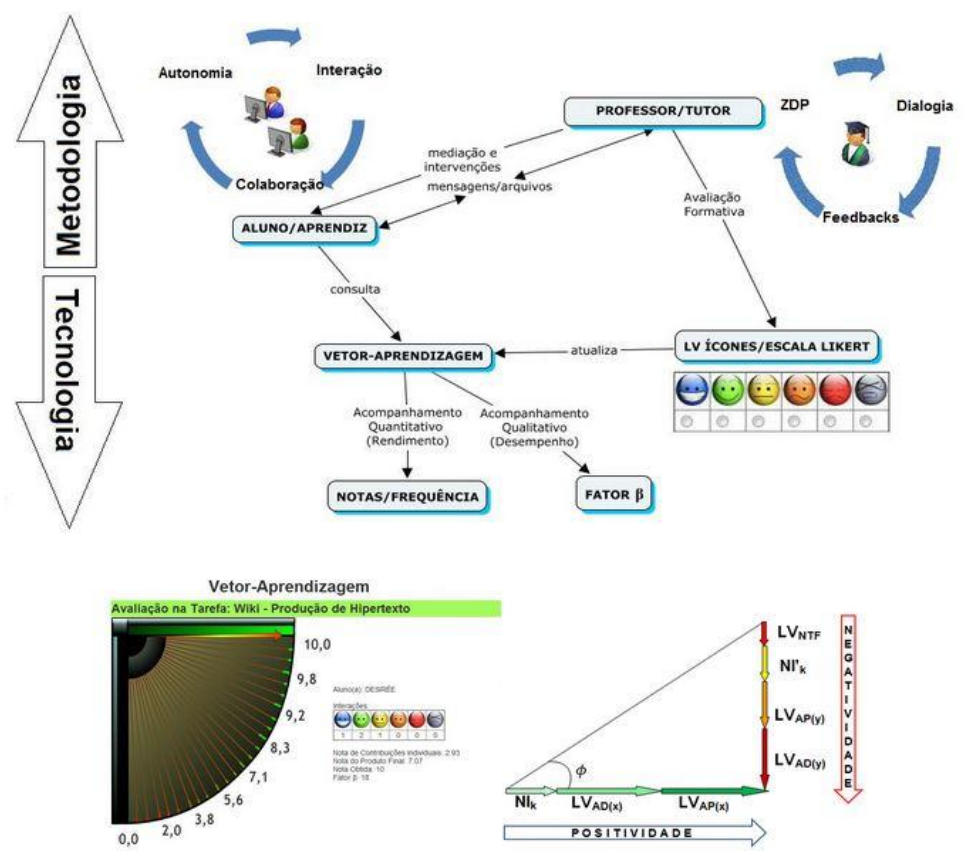

Fonte: adaptado de Sales (2010)

\section{Desenvolvimento}

Os Learning Vectors (LV) "são representações geométricas vetoriais concebidas para automatizar o processo de avaliação qualitativo/quantitativo em Ambientes Virtuais de Aprendizagem (AVA)" (SALES, 2010).

Eles foram desenvolvidos para o Moodle 1.9 e mostraram-se satisfatório no seu intuito. Com a atualização do Moodle para a versão 2.0 e família, é necessário atualizálos para que possam se adaptar às novas funcionalidades deste AVA.

Desenvolvido como um plugin de extensão ao Moodle e aplicado como ferramenta de avaliação nos fóruns, chats, tarefas e wikis, os LV são instrumentos para análise e acompanhamento de participações de cursistas nessas atividades e foram criados para uso em cursos semipresenciais ou a distância.

A visualização do constante e contínuo desempenho e rendimento do aluno é disponibilizada quando ele acessa o mecanismo denominado Vetor-Aprendizagem.

Uma escala de menções qualitativas associada a uma escala iconográfica, LV Ícones, é utilizada pelo Professor/Tutor para avaliar as mensagens ou arquivos enviados pelos alunos (Figura 2) durante as atividades no AVA.

Figura 2 - Menções qualitativas e LV Ícones

\begin{tabular}{|c|c|c|c|c|c|c|}
\hline $\begin{array}{l}\text { Menções } \\
\text { Qualitativas }\end{array}$ & $\begin{array}{l}\text { 三 } \\
\text { 总 } \\
\text { 总 }\end{array}$ & 站 & 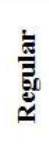 & $\stackrel{8}{E}$ & 穵 & 竞 \\
\hline LV Ícones & & & & & & \\
\hline
\end{tabular}


Os LV ainda trazem uma referência ao nível de desempenho do aluno no curso. Expresso pelo Fator $\beta$, para Sales, Barroso e Soares (2012):

\begin{abstract}
O Fator $\beta$ é um indicador qualitativo não-linear (...) o Fator $\beta$ relaciona e associa os aspectos subjetivos tomados a partir dos itens de apreciação da Escala de Menções e transforma-os numa escala formal de avaliação definida por valores que exprimem a positividade em relação à negatividade do desempenho do aluno.
\end{abstract}

O desenvolvimento computacional desse modelo ocorreu a partir da extensão e reuso de códigos das ferramentas do próprio AVA Moodle (MOODLE, 2012), que é um software livre muito bem documentado, modularizado e desenvolvido em uma das mais populares linguagens de programação para criação de aplicativos web, o PHP.

Por essa razão, as novas instâncias: Fórum LV, Tarefa LV, Wiki LV e Chat LV, bem como o controle de frequência puderam ser facilmente integradas e adaptadas a esse ambiente.

Nas próximas seções, apresenta-se a reengenharia computacional aplicada no desenvolvimento do SIG@LV, hoje aplicado em turmas do Instituto Federal do Ceará e Instituto UFC Virtual.

\title{
3. Apresentação do software
}

Discutem-se as alterações no plugin LV para o Moodle 1.9 que são necessárias para fazê-lo funcionar no Moodle versão 2.0 e subsequentes, doravante intitulado Moodle 2.X. Essa versão trouxe consigo muitas reconstruções em seu código, tornando algumas funções obsoletas e inutilizando outras; e modificações nos requisitos mínimos para sua instalação.

O plugin LV foi desenvolvido em PHP por essa ser a linguagem de programação adotada pelo Moodle. Foi criado como um módulo a ser adicionado a um curso e permite a configuração de atividades presenciais e/ou a distância, "bem como o cômputo de notas e apresentação de resultados parciais e finais" (SALES, 2010).

Entretanto, a atualização do Moodle 1.9 e versões para 2.X trouxe a obrigatoriedade de adaptação do plugin a novos requisitos técnicos do AVA escolhido.

Os seguintes itens alterados no Moodle requereram especial atenção: modificação na camada de acesso ao banco de dados; unificação do sistema de avaliação; criação de objetos para configuração e renderização das páginas; criação de métodos que restringem o acesso à recursos; e, migração para YUI 3.

Sendo obrigatório a reformulação do código para garantir o funcionamento correto do módulo e, a fim de adotar o paradigma da orientação a objetos, aproveitou-se a oportunidade para fazer uma completa reconstrução da implementação nos seguintes aspectos:

a) Camada de acesso ao banco

As bibliotecas para manipulação de dados forneciam funções para inserção, recuperação e deleção de informação, entre outras. Tais funções tornaram-se obsoletas na versão 2.X, sendo obrigatório o uso de um objeto de escopo global chamado \$DB para efetuar qualquer operação de manipulação de dados.

b) Renderização de Página e elementos HTML 
A exibição de páginas HTML, a configuração de seus headers, a exibição de seus footers e os breadcumbs eram exibidos por funções atualmente obsoletas. Foram criados dois novos objetos de escopo global que juntos contemplam todas as responsabilidades exercidas por elas. São eles: \$PAGE e \$OUTPUT.

A variável \$PAGE configura uma página, permitindo que scripts e/ou folhas de estilo sejam postos no documento HTML a ser exibido. Inclui ainda funções para criação de breadcumbs no menu superior do Moodle.

O objeto \$OUTPUT renderiza a página configurada no browser. Ele, por meio de seus métodos, quem cria toda a estrutura HTML a ser exibida. Exibe o header e os breadcumbs configurados em \$PAGE e todo o conteúdo restante da página.

Além dessas duas variáveis, algumas funções obsoletas foram substituídas por métodos estáticos, dentre as quais destaca-se a função print_table(), cuja operação foi transferida para html_writer::table(). Ela é responsável pela impressão de tabelas HTML, muito utilizadas pelo plugin para a exibição do desempenho dos alunos no curso e para configuração das atividades.

c) Sistema de avaliação

Nas versões anteriores a 2.X, cada módulo era responsável por seu sistema de notas e, embora fossem semelhantes entre si, eram distintos do ponto de vista do Moodle. Era possível adicionar a escala qualitativa de apreciação (Muito Bom, Bom, Regular, Não satisfatório, Insuficiente) a cada ferramenta estendida LV sem prejuízo aos demais módulos.

Na versão Moodle 2.X, há um único sistema de notas a ser compartilhado entre todos. Essa importante alteração implica em adicionar a escala ao sistemas de notas do Moodle, o que seria um fator limitador do plugin, visto que não poderia ser utilizado com qualquer outro plugin que também alterasse esse sistema.

d) Acesso a recursos

Todas as páginas devem explicitar uma chamada "require_login" caso seja necessário o seu uso, pois require_capability não faz mais o require_login automaticamente, ocasionando o acesso de usuários não-logados à páginas com conteúdo sensível, como notas de alunos, por exemplo.

e) Javascript

O plugin LV utiliza o JQuery ${ }^{1}$ como biblioteca javascript. Entretanto, o Moodle recomenda que se utilize a sua biblioteca padrão $\mathrm{YUI}^{2}$. A partir do Moodle 2.X, o YUI 2 foi substituído pelo YUI 3 com o objetivo de melhorar a perfomance e padronizar o uso dos códigos javascript.

A padronização começa pelo armazenamento de todos os códigos javascript dentro da namespace global $\mathrm{M}$, criada para reduzir problemas de escopo durante o carregamento de variáveis pelo YUI Loader. Recomenda-se a nomeação do arquivo .js principal do módulo de module.js.

Como o Moodle propõe uma formalização, decidiu-se por adotar tais requisições no desenvolvimento da nova versão do plugin e remover o JQuery de todos os scripts, substituindo chamadas às suas funções por equivalentes no YUI.

Após implementada todas as alterações no plugin LV para o Moodle 1.9, as interfaces serão apresentadas a seguir.

\footnotetext{
${ }^{1}$ disponível em http://jquery.com/

${ }^{2}$ disponível em http://yuilibrary.com/
} 


\subsection{A implementação do Modelo LV no MOODLE e interfaces}

Em Fórum LV a nova funcionalidade permite que as avaliações sejam salvas sem a necessidade de rolar a página até sua parte inferior e "Salvar" (Figura 3).

Figura 3 - Fórum LV

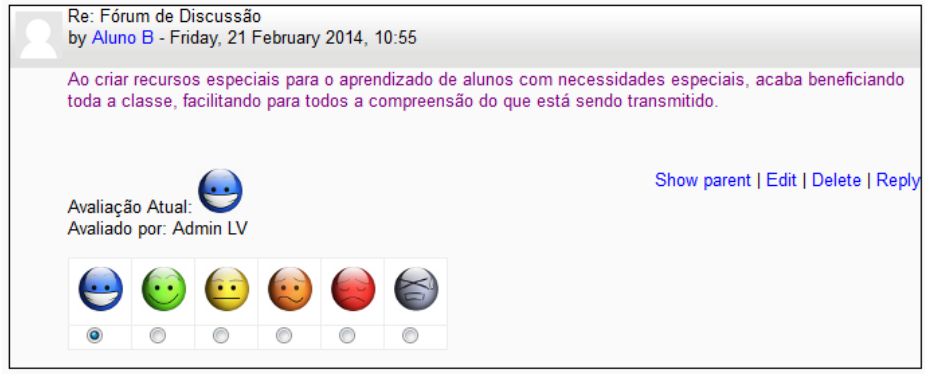

A cada mensagem avaliada, o Vetor-Aprendizagem avança angularmente $(\Delta)$ de acordo com a configuração de mensagens mínimas selecionadas $(\mathrm{M})$, por exemplo, caso se configure o Fórum LV para que se avalie no mínimo duas mensagens $(\mathrm{M}=2)$ será necessário avaliá-las com dois LV Ícones azuis, ocasião em que Vetor-Aprendizagem tem avanço angular de $45^{\circ}$ para cada mensagem avaliada, assim o aluno tira dez na atividade (Figura 4).

Figura 4 - Número mínimo de mensagens avaliadas X Notas X Fator $\beta$ X Avança angular do Vetor-Aprendizagem em Fórum LV

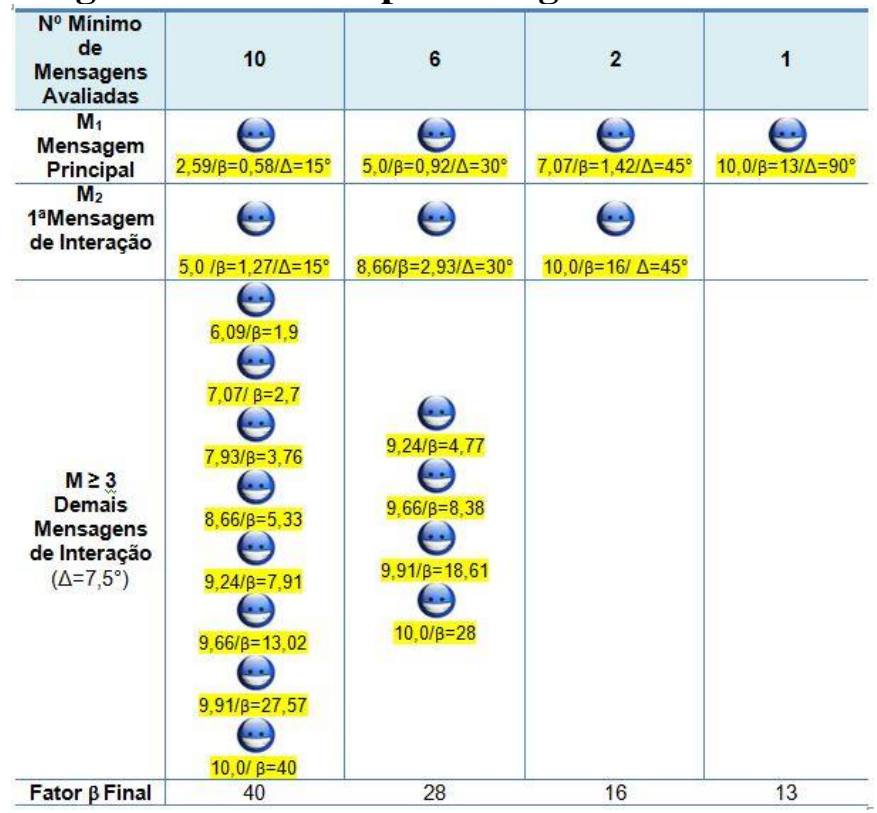

Fonte: Elaborada pelo autor

Para Tarefas LV a Escala de Ícones foi estendida permitindo uma avaliação bidimensional de critérios (Figura 5).

Figura 5 - Tarefa LV 


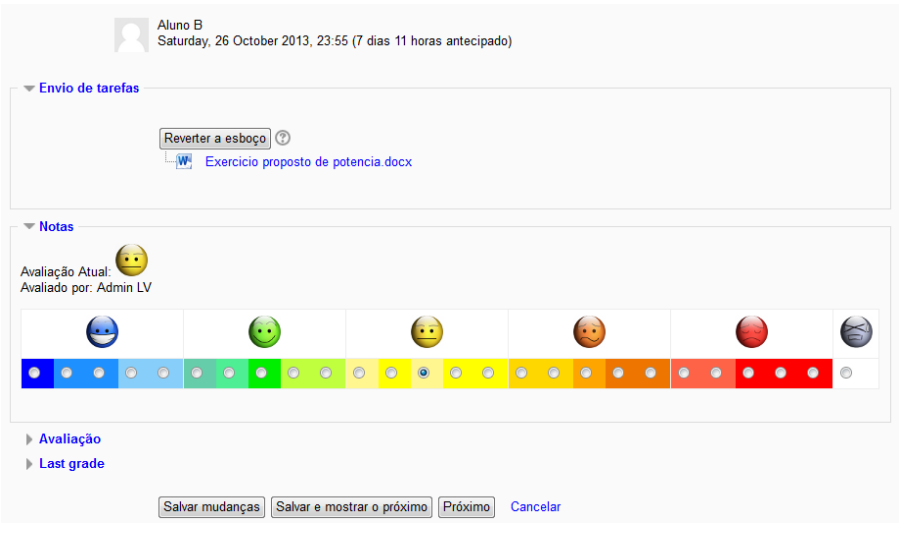

A relação LV Ícone/Notas é apresentada na Figura 6, que relaciona a cada cor principal do ícone outras cinco totalidades, também estabelece uma matriz bidimensional na avaliação entre os critérios "Domínio de conteúdo" e "pontualidade/apresentação".

Figura 6 - Escala de avalição em Tarefa LV

\begin{tabular}{|c|c|c|c|c|c|c|}
\hline \multicolumn{7}{|c|}{ Notas LV Tarefa/Portfólio } \\
\hline \multirow{2}{*}{$\frac{\text { LV ícone }}{\Theta}$} & \multirow{2}{*}{$\begin{array}{c}\text { Escala } \\
\text { Qualitativa } \\
\text { Muito Bom } \\
\text { Exoelente domínio } \\
\text { de conteúdo }\end{array}$} & \multicolumn{5}{|c|}{$\begin{array}{c}\text { Valor Associado a Dominio de Conteúdo- - } \\
\text { Pontualidade/Apresentação }\end{array}$} \\
\hline & & 10,0 & 9,98 & 9,91 & 9,81 & 9,66 \\
\hline 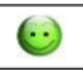 & $\begin{array}{c}\text { Bom } \\
\text { Bom domínio de } \\
\text { conteúdo }\end{array}$ & 9,47 & 9,24 & 8,97 & 8,66 & 8,31 \\
\hline$(\cdot)$ & $\begin{array}{l}\text { Regular } \\
\text { Razóvel domínio } \\
\text { de conteúdo }\end{array}$ & 7,93 & 7,52 & 7,07 & 6,59 & 6,09 \\
\hline & $\begin{array}{c}\text { Fraco } \\
\text { Fraos domínio de } \\
\text { conteúdo }\end{array}$ & 5,56 & 5,00 & 4,42 & 3,83 & 3,21 \\
\hline & $\begin{array}{l}\text { Não Satisfatório } \\
\text { Ideias desconexas }\end{array}$ & & & & & \\
\hline & $\begin{array}{l}\text { e sem muita } \\
\text { relacasocoma a } \\
\text { atividade } \\
\text { proposta }\end{array}$ & 2,59 & 1,95 & 1,31 & 0,70 & 0,00 \\
\hline & $\begin{array}{l}\text { Neutro } \\
\text { Arquivo sem } \\
\text { relaçioo alguma } \\
\text { omm o tema } \\
\text { proposto ou } \\
\text { arquito om } \\
\text { branco }\end{array}$ & \multicolumn{5}{|c|}{ Não Agrega Nota } \\
\hline
\end{tabular}

No Wiki LV, quando a opção "Grupos" for ativada, cada contribuição individual poderá ser avaliada (Figura 7).

\section{Figura 7 - Wiki LV}

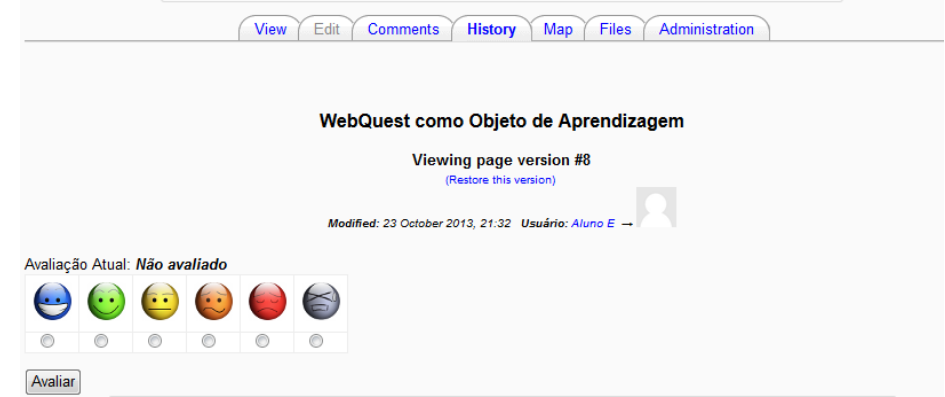

A avaliação de uma página hipertextual construída no Wiki LV pode ser apenas no "Produto Final", contribuições individuais igual a zero, mas caso se deseje considerar 
as contribuições individuais, mínimo uma e no máximo cinco, avaliam-se aluno por aluno no "histórico" da página wiki Moodle (Figura 8).

Figura 8 - Avaliação em Wiki LV

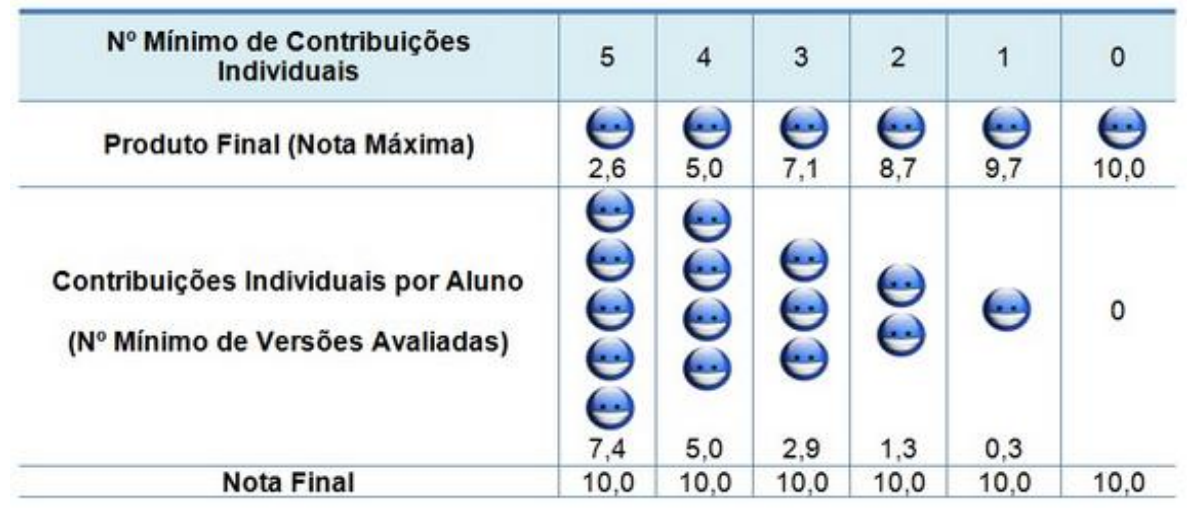

No Chat LV o Professor/Tutor avalia "just in time" à proporção que o diálogo ocorre de forma síncrona (Figura 9).

Figure 9 - Chat LV

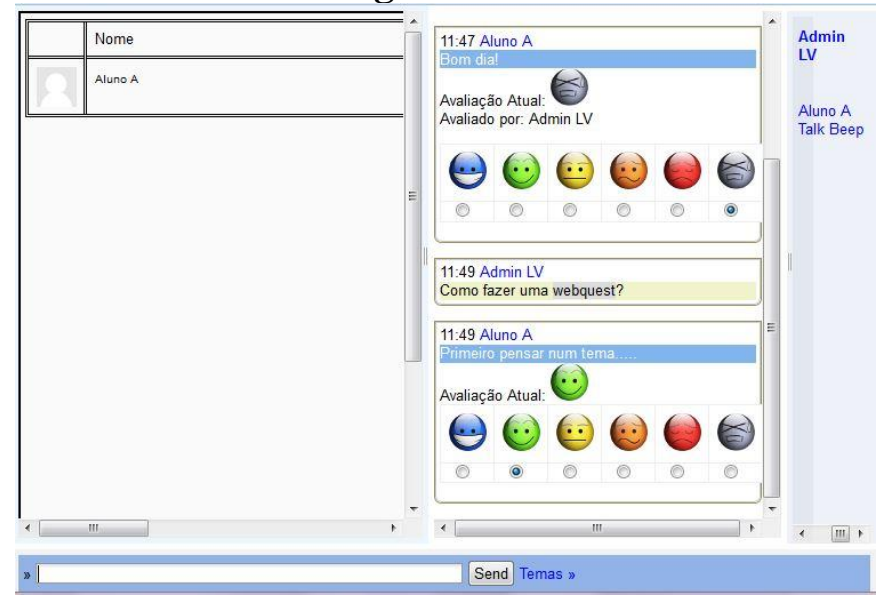

Por fim, o sistema apresenta ao Professor/Tutor as notas de cada cursista e sua situação final no curso. Cada aluno visualiza apenas suas notas, enquanto que o Professor/Tutor ver as notas de todos os alunos, podendo exportar o mapa de notas na forma de documento pdf (Figura 10). 
Figura 10 - Bloco de Notas LV

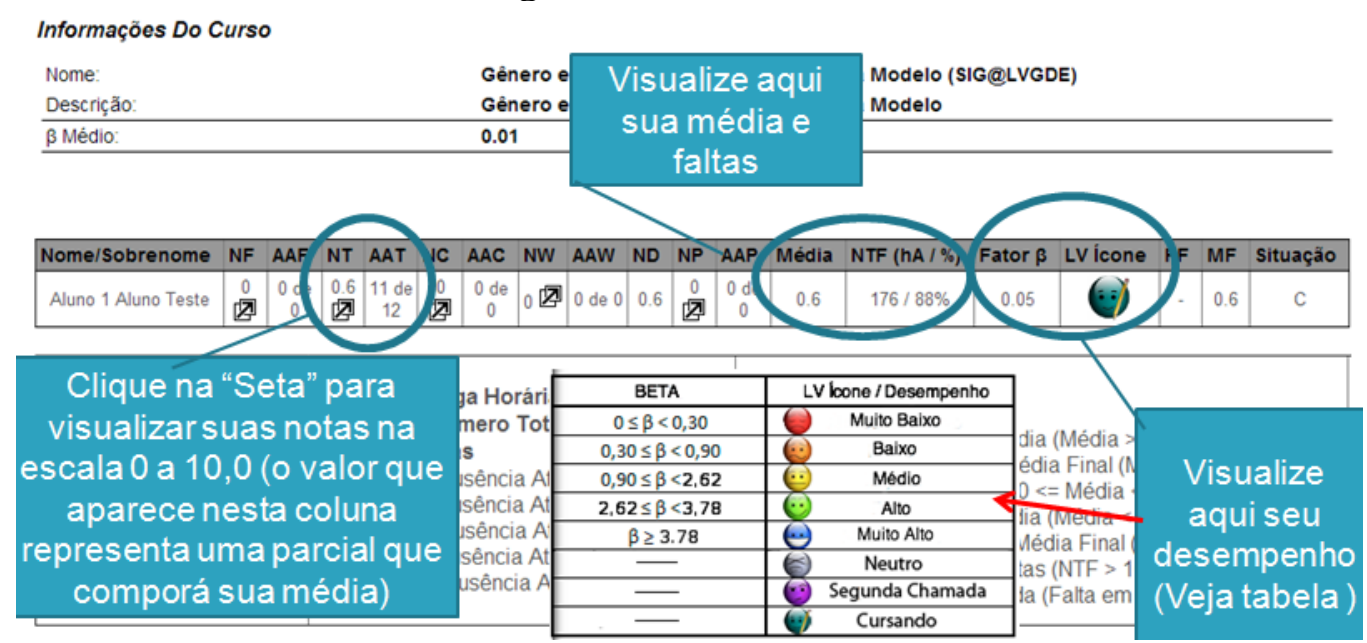

O diferencial do mapa de notas é a inclusão da coluna com as notas de quizzes já integrada e a coluna NTF, que apresenta o número total de faltas do cursista em todas as atividades presenciais e a distância.

\section{Considerações finais}

A atualização do Moodle da versão 1.9 para 2.0 trouxe mudanças significativas no núcleo de seu código e obrigou que a implementação do plugin LV, antes aplicado à versão 1.9, tivesse que ser revista, possibilitando o seu aprimoramento, tanto em termos de manutenção como em performance, o que findou com a criação do plugin SIG@LV em total conformidade com as recomendações da nova versão do Moodle.

No Moodle versão 2.X levantaram-se todas as alterações obrigatórias para a correta execução do plugin SIG@LV; Indicou-se a existência de padronização na construção de extensões ao Moodle; Propôs-se a adoção do paradigma de Orientação a Objetos; e, finalmente, fez-se a adaptação e realocamente do código existente em novas estruturas de código.

Validado em turmas semipresenciais e como suporte presencial, o resultado das ações aqui explanadas foi a construção de um sistema de avaliação que possibilita uma avaliação formativa, gerencia a frequência do aluno e retorna os dados na forma de tabela para o devido acompanhamento didático-pedagógico de forma processual.

Como trabalhos futuros, propõe-se estender a integração para outras ferramentas do Moodle, assim como para a modalidade em "Grupos separados" e "Grupos visíveis", uma vez que, os LV, com exceção do Wiki LV, só se aplicam a 'Nenhum Grupo”.

\section{Referências}

SALES, G. L. Learning Vectors (LV): um modelo de avaliação da aprendizagem em EaD online aplicando métricas não-lineares. Tese Doutorado. Departamento de Engenharia de Teleinformática. Universidade Federal do Ceará. 2010. 239f.

SALES, G. L.; BARROSO, G. C.; SOARES, J. M. Learning Vectors (LV): Um Modelo de Avaliação Processual com Mensuração Não-Linear da Aprendizagem em EaD online. In: Revista Brasileira de Informática na Educação, Volume 20, Número 1, 2012. 